\section{The introduction of digital dental technology into BDS curricula}

\author{
C. Chatham, ${ }^{1}$ M. H. Spencer, ${ }^{1}$ D. J. Wood ${ }^{2}$ and A. Johnson*3
}

IN BRIEF

- Ascertains the current extent of digital dental technology teaching in UK dental schools.

- Informs readers about the types of digital dental technology currently being taught and used in UK dental schools.

- Explores why this rapidly developing technology is not currently being taught in some UK dental schools.

The aim of this study was to determine the degree to which digital dental technologies have been introduced into the curricula of UK dental schools. A survey was carried out of all the UK dental schools that teach undergraduate dental students. The survey contained six questions and was designed to determine if digital dental technology techniques or systems were being taught in the curricula, what these techniques were, and whether the school dental laboratories supported these techniques. Sixteen schools were surveyed and 11 replied: a response rate of 69\%. Forty-five percent of the schools that replied did not teach digital dental technology in their curriculum. Of the 55\% of schools who did teach digital dental technology, 50\% gave lectures or demonstrations while the other 50\% allowed practical involvement by the student. Two thirds of these stated that not all the students participated in practical usage. Seventy-three percent of the schools that replied had dental laboratories using some, but not all the digital dental technology techniques listed. Eighty percent of the schools that were not teaching digital dental technology said it was because it was not included in the curriculum, and $20 \%$ stated it was due to a lack of technical expertise or support.

\section{INTRODUCTION}

Computer aided design and Computer aided manufacture (CAD/CAM) was first introduced into dentistry in the 1970s with Duret and Preston ${ }^{1}$ being the first workers to use it. The 1980s saw the development of the CEREC system, which went a long way to establishing $\mathrm{CAD} / \mathrm{CAM}$ as a routine technology in many dental laboratories and some clinical practices. ${ }^{2}$

Digital technology has seen a rapid advance recently in dentistry. ${ }^{3}$ Individual and production centre commercial dental laboratories are currently producing restorations or appliances using the following digital techniques:

- Model scanning

- Computer aided design of indirect restorations

- Computer aided design for removable partial dentures

- Milling of indirect restorations/ substructures (alloys mostly outsourced to milling centres, ceramics capable of being produced in-house but also outsourced to milling centres)

'Dental student, ${ }^{2}$ Senior University Teacher, ${ }^{3}$ Senior Lecturer, School of Clinical Dentistry, University of Sheffield ${ }^{*}$ Correspondence: Dr A. Johnson

Email: a.johnson@sheffield.ac.uk

\section{Refereed Paper}

Accepted 29 August 2014

DOI: 10.1038/sj.bdj.2014.1049

${ }^{\circ}$ British Dental Journal 2014; 217: 639-642
- Additive manufacturing of indirect restorations (wax printing and selective laser melting)

- Additive manufacturing of removable partial dentures (wax pattern printing for conventional lost wax casting or selective laser melting. The wax pattern capable of being produced in-house or outsourced, the selective laser melting outsourced to a commercial company)

- Additive manufacturing of models.

Many dental devices are currently being produced using digital techniques to a greater or lesser extent, including veneers, crowns and bridges, removable partial dentures, complete dentures, implants and implant framework and customised maxillofacial prostheses. ${ }^{2-8}$ Digital technology is already changing dentistry and will replace more and more of the traditional techniques used to fabricate dental restorations as well as enabling new, high performance, high accuracy, materials to be introduced. ${ }^{5,9}$

A proportion of teachers and academics, employed in UK dental schools, may have received their professional training before the advent of digital dental technology took place. They will undoubtedly be interested in these new technologies and developing new skills as part of continuing education. However, current commitments, time constraints and cost implications may hinder opportunity. Students on the other hand will have grown up in a world of digital innovation and technology. Present day students are used to multitasking and using computers in an interactive way and will expect innovative cutting edge technology to be evident in their curriculum.

In the authors' school this technology has largely been driven by research, the introduction of these technologies into the BDS curriculum, and the use in production laboratories following on from the research interest. In order to introduce these new technologies sufficient time must be given for teachers to become familiar with these technologies and a good deal of capital investment in space and equipment will need to be made (Figs 1a-b).

It is of interest to determine if undergraduate curricula have kept pace with the recent innovations in digital dental appliance production currently being employed by increasing numbers of dental laboratories. To answer this question a survey of the digital technology techniques and systems currently being taught in UK undergraduate curricula was carried out of all the UK dental schools that teach undergraduate dental students.

The purpose of this questionnaire study was to determine the degree to which digital dental technologies have been introduced into the curricula of UK dental schools that teach undergraduate dental students. 


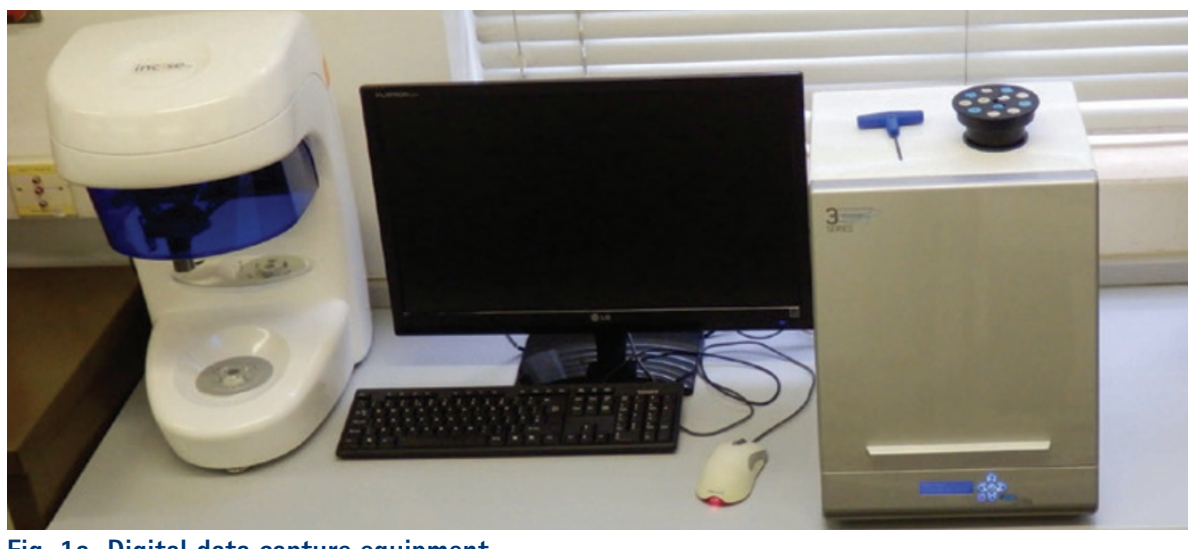

Fig. 1a Digital data capture equipment

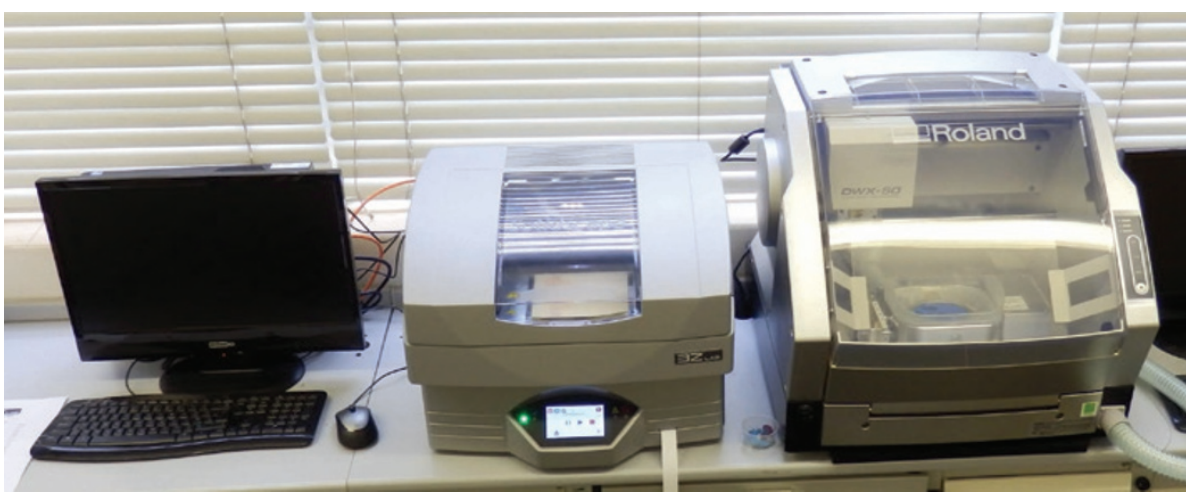

Fig. 1b Wax printer (left) and milling unit (right)

The hypothesis for this project would be that these new digital technologies might not have been fully introduced into BDS curricula, because of cost implications and a lack of staff/expertise.

\section{DETAILS OF THE QUESTIONNAIRE}

A survey was designed and sent to the deans of all 16 schools in the UK that teach undergraduate dental students. The survey questions, together with the answers, are shown in the results. Ethical approval for this project was obtained from the University of Sheffield and the survey was designed to take no longer than five minutes to complete. The survey returns were completely anonymous.

The survey contained six questions and was designed to identify if digital dental technology techniques or systems were being taught, what these techniques were and whether the school or hospital dental laboratories supported these techniques.

\section{THE SURVEY QUESTIONS AND THE REPLIES RECEIVED}

Eleven out of the sixteen schools replied, a 69\% return. The questions asked and the replies received are shown below.

\section{Question 1. Do you teach digital} dental technology techniques to your undergraduate students?

See Table 1 for the replies to question 1 .
Question 2. Which year(s) of students do you teach this to?

See Table 2 for the replies to question 2 .

Question 3. What digital techniques do you teach?

1. Intra-oral scanning

2. Model scanning

3. Computer aided design (CAD) of indirect restorations

4. Computer aided design (CAD) of removable partial dentures

5. Milling of indirect restorations/substructures

6. Additive manufacturing of indirect restorations (wax printing/laser sintering)

7. Additive manufacturing of removable partial dentures (wax printing)

8. Other:

The replies to question 3 can be seen in Table 3.

Question 4. Do your undergraduate students use these techniques practically? Or, do they just receive lectures/demonstrations on these?

See Table 4 for the replies to question 4 .

Question 5. Do your technology laboratories use digital technology during the production of patient appliances? If yes which of the techniques listed below do they use?

1. Intra-oral scanning

\begin{tabular}{l|l}
\hline Table 1 & Question 1 replies \\
\hline Reply & Number of schools \\
\hline Yes & 6 \\
\hline No & 5
\end{tabular}

\begin{tabular}{|l|l|}
\hline \multicolumn{2}{|l|}{ Table 2 Question 2 replies } \\
\hline Student year & Number of schools \\
\hline $1^{\text {st }}$ & 1 \\
\hline $2^{\text {nd }}$ & 1 \\
\hline $3^{\text {rd }}$ & 3 \\
\hline $4^{\text {th }}$ & 3 \\
\hline $5^{\text {th }}$ & 2 \\
\hline
\end{tabular}

2. Model scanning

3. Computer aided design (CAD) of indirect restorations

4. Computer aided design (CAD) of removable partial dentures

5. Milling of indirect restorations/ substructures

6. Additive manufacturing of indirect restorations (wax printing/ laser sintering)

7. Additive manufacturing of removable partial dentures (wax printing)

8. Other:

The answers to question 5 can be seen in Table 5. Of the 11 schools that replied eight had laboratories using digital dental techniques to produce appliances for their students' patients; three schools did not.

Question 6. If you are currently not using digital technologies in your teaching, do you intend to do so in the near future? If not why:

1. Cost

2. Lack of technical expertise/support

3. Lack of space

4. Not included in the current curriculum.

The replies to question 6 are shown in Table 6.

\section{DISCUSSION}

It can be seen that not all UK dental schools have embraced the digital dental technology 'revolution'. In addition, not all the dental laboratories within dental schools that support undergraduate patient work provision are using digital technology.

Tables 1-6 show the results of the survey. Just over half the schools, six out of 11 , that replied teach some form of digital technology in their curricula (Table 1). This teaching appears to be spread over all five years of the BDS course (Table 2). The 


\begin{tabular}{|l|l|}
\hline \multicolumn{2}{|l|}{ Table 3 Question $\mathbf{3}$ replies } \\
\hline Techniques taught & Number of schools \\
\hline 1 & 3 \\
\hline 2 & 4 \\
\hline 3 & 6 \\
\hline 4 & 1 \\
\hline 5 & 6 \\
\hline 6 & 1 \\
\hline 7 & 1 \\
\hline Other & 0 \\
\hline
\end{tabular}

\begin{tabular}{|c|c|}
\hline $\begin{array}{l}\text { Techniques used in school } \\
\text { production laboratories }\end{array}$ & $\begin{array}{l}\text { Number of } \\
\text { schools }\end{array}$ \\
\hline 1 & 3 \\
\hline 2 & 6 \\
\hline 3 & 7 \\
\hline 4 & 1 \\
\hline 5 & 7 \\
\hline 6 & 2 \\
\hline 7 & 0 \\
\hline Other & 0 \\
\hline
\end{tabular}

\begin{tabular}{|c|c|}
\hline $\begin{array}{l}\text { Reason for not using digital } \\
\text { technologies }\end{array}$ & $\begin{array}{l}\text { Number of } \\
\text { schools }\end{array}$ \\
\hline 1 & 0 \\
\hline 2 & 1 \\
\hline 3 & 0 \\
\hline 4 & 4 \\
\hline $\begin{array}{l}\text { Do you intend to introduce } \\
\text { these technologies into your } \\
\text { curriculum in the future? }\end{array}$ & 1 \\
\hline
\end{tabular}

most popular techniques taught were 'CAD of indirect restorations, milling of indirect restorations/substructures, model scanning and intra-oral scanning' (Table 3). Half the schools that replied, three out of six, only taught digital technology using lecture/ demonstration only with one school allowing hands-on participation by all students and two schools allowing hands-on participation by only some of the students (Table 4). The technology laboratories that support BDS student patient treatment are using at least some of the digital technology techniques described in the survey questionnaire, with the exception of the additive manufacturing of removable partial dentures (wax printing) (Table 5). The main reasons

\begin{tabular}{|c|c|c|c|}
\hline & $\begin{array}{l}\text { Lectures and } \\
\text { demonstrations only }\end{array}$ & $\begin{array}{l}\text { All students use the } \\
\text { techniques practically }\end{array}$ & $\begin{array}{l}\text { Only some students use } \\
\text { the techniques practically }\end{array}$ \\
\hline Number of schools & 3 & 1 & 2 \\
\hline
\end{tabular}

given for not teaching digital technologies were given as 'not included in the current curricula' and 'lack of technical expertise/ support' (Table 6).

All the techniques listed in the survey are currently being employed in commercial dental laboratories known to the authors to produce dental appliances for UK dental practice. As van Noort ${ }^{3}$ and Beuer et al. ${ }^{5}$ have stated in recent papers on this subject, digital dentistry is already here, will expand in the near future and completely change the way we manufacture our dental appliances. This will inevitably lead to the development of novel dental materials and change the direction of dental materials research.

Not all dental schools currently appear to be at the forefront of, or indeed participating at all, in this digital area, with commercial companies and commercial dental laboratories leading the way with development and practical implementation.

The authors' school has embraced digital technologies and all students have practical experience of digital techniques at some stage of their undergraduate course. However, there have been significant barriers, some of which have been highlighted by this study. Digital technology is not cheap and the school has made an investment of $£ 80,458.00$ over the last two years to provide equipment; staff time was also provided to allow for academic and technical teaching staff to train in the use of these technologies.

If digital technologies and their novel materials are not introduced into dental curricula it will be difficult for our newly graduated dentists to fully understand the range of new technologies available to them and for them to make informed decisions regarding the most appropriate techniques, systems or materials to choose from for different dental applications. Future dental materials research will also, inevitably, move more towards these novel techniques and if dental schools wish to remain at the "cutting edge', investment in these new technologies is essential.

Given the high cost of equipment purchase and the investment of time and expense in staff training required to introduce digital dental technology into dental curricula, a novel solution may be to involve equipment manufacturers and commercial dental laboratories in undergraduate teaching and practical demonstrations. Both equipment manufacturers and commercial laboratories have a vested interest in introducing the dental undergraduate to digital dental technology, current techniques and materials choices. As van Noort stated: "the future of dental devices is digital'; however, the authors would suggest that it will only be truly digital when these systems and devices are embedded in dental undergraduate curricula and the onsite dental laboratories that support it.

This survey did not include selective laser melting (SLM) as this technology is as yet probably beyond the reach, financially, of most individual dental laboratories. It will eventually be available via outsourcing to large commercial SLM centres and will eventually negate the need for a wax pattern and lost wax casting altogether.

It may be interesting to conduct a similar survey of dental technology education establishments to find out what is being taught to future dental technologists.

\section{CONCLUSIONS}

- Just under half the dental schools that replied to the survey, five out of six, for one reason or another, do not have any digital dentistry in their curricula

- Digital dentistry is here to stay and is allowing a whole new generation of restorative materials to be developed on the back of these novel production methods. Dental school curricula must keep pace with this if our undergraduate students are to be able to make informed judgements on the most appropriate appliances and materials choice that can be used for the care of their patients

- Of the digital techniques taught by dental schools the computer aided design (CAD) and milling of appliances were the most popularly taught techniques.

1. Duret F, Preston J D. CAD/CAM imaging in dentistry Curr Opin Dent 1991; 1: 150-154.

2. Miyazaki T, Hotta Y, Kuni J, Kuiyama S, Tamaki Y. A review of dental CAD/CAM: current status and future perspectives from 20 years of experience. Dent Mater 2009; 28: 44-56.

3. van Noort R. The future of dental devices is digital. Dent Mater 2012; 28: 3-12.

4. Yates J M, Wildgoose D G, van Noort R. Correction of a mandibular asymmetry using custom-made titanium onlay. J Plast Reconstr Aesthet Surg 2009; 62: 247-250.

5. Beuer F, Schweiger J, Edelhoff D. Digital dentistry: an overview of recent developments for CAD/CAM generated restorations. Br Dent J 2008; 
204: 505-511.

6. Bidra A S, Taylor T D, Agar J R. Computer-aided technology for fabricating complete dentures: Systematic review of historical background, current status, and future perspectives. J Prosthet Dent 2013; 109: 361-366.
7. Lin W-S, Harris B T, Morton D. The use of a scannable impression coping and digital impression technique to fabricate a customised anatomic abutment and zirconia restoration in the esthetic zone. J Prosthet Dent 2013; 109: 187-191.

8. Miyaki T, Hotta Y. CAD/CAM systems available for the fabrication of crown and bridge restorations. Aust Dent J 2011; 56: 97-106.

9. Andreiotelli M, Kamposiora P, Papavasiliou G. Digital data management for CAD/CAM technology. An update of current systems. Eur J Prosthodont Restor Dent 2013; 21: 9-15. 